\title{
EQUIPMENT
}

UDC 666.1.031

\section{BOUNDARY CONDITIONS FOR CALCULATING THE REGENERATOR AND CHECKER BRICKWORK IN A GLASSMAKING FURNACE}

\section{Ya. Dzyuzer ${ }^{1}$}

Translated from Steklo i Keramika, No. 7, pp. 7 - 10, July, 2013.

An engineering method for calculating the temperature of the regenerator brickwork in a glassmaking furnace is proposed. Recommendations are made concerning the structure of the checkerwork of a single-turn regenerator in a furnace with a horseshoe flame.

Key words: glassmaking furnace, regenerator, enthalpy, temperature, refractory.

The energy efficiency and run of a glassmaking furnace are largely determined by the operating conditions of the regenerator. Two problems are solved in designing the regenerative system. One problem is to determine the heating surface of the checkerwork, for which a prescribed heating temperature of air for combustion is provided. The second one is associated with the development of a structure for the regenerator brickwork as well as picking a material for the checker elements which guarantee long-time operation and minimum heat losses to the ambient environment. Improvement of the brickwork structure over the height of the regenerator also makes it possible to decrease the cost of building the regenerator. A correct approach to solving the second problem employs well-supported values for the temperature of the interior surface of the regenerator in the calculation and design processes.

The engineering method of calculating the temperature of the brickwork is based on the assumptions that the heattransfer process is stationary and that the temperature of the brickwork surface corresponds to the temperature of the gases coming into contact with this surface.

The conditions of the calculation (Fig. 1a) specify the temperature and flow of the flue gases at entrance into the regenerator $t_{f}^{\prime}$ as well as the temperature of the air at the entrance into and exit from the chamber $\left(t_{\mathrm{a}}^{\prime}\right.$ and $\left.t_{\mathrm{a}}^{\prime \prime}\right)$ and the air flow. The aim of the calculation is to determine the temperature of the flue gases at the exit from the chamber $t_{\mathrm{f}}^{\prime \prime}$ the average temperature of the flue gases at the top $\overline{t_{\text {f. top }}}$ and bottom

1 First President of Russia B. N. El'tsin Ural Federal University, Ekaterinburg, Russia (e-mail: vdzuzer@yandex.ru). $\overline{t_{\text {f. bot }}}$ of the checkerwork as well as the distribution of the temperature of the flue gases over the height of the checkerwork.

The approximate temperature of the flue gases at the exit from the regenerator can be determined using the wellknown it-diagram for natural gas (curve - products of combustion in the absence of air) [1]. The exact value of the temperature can be found by successive approximations of the product $c_{\mathrm{f}} t_{\mathrm{f}}$ to the computed value of the enthalpy of the flue gases.

The heat content of the flue gases behind the regenerator can be found from the heat-balance equation, constructed so as to take account of the flow of atmospheric air into the regenerator during the venting period and the heat losses through the brickwork. In expanded form the equation is

$$
V_{\mathrm{f}}^{\prime}\left(i_{\mathrm{f}}^{\prime}-i_{\mathrm{f}}^{\prime \prime}\right)=\frac{1}{\eta} V_{\mathrm{a}}\left(i_{\mathrm{a}}^{\prime \prime}-i_{\mathrm{a}}^{\prime}\right)+m_{\mathrm{a}} V_{\mathrm{f}}^{\prime}\left(i_{\text {in }}^{\prime \prime}-i_{\text {in }}^{\prime}\right),
$$

where $V_{\mathrm{f}}^{\prime}$ is the flow of the flue gases at entrance into the regenerator, $\mathrm{nm}^{3} / \mathrm{sec}$, in conventional 'normal' meters; $V_{\mathrm{a}}=B L_{\alpha}$ the air flow to combustion, $\mathrm{nm}^{3} / \mathrm{sec} ; B$ is the gas flow, $\mathrm{nm}^{3} / \mathrm{sec} ; L_{\alpha}$ is the air flow to combustion of $1 \mathrm{~m}^{3}$ of gas with the actual air flow ratio $\alpha=1.1 \mathrm{~m}^{3} / \mathrm{m}^{3} ; i_{\mathrm{f}}^{\prime}=c_{\mathrm{f}}^{\prime} t_{\mathrm{f}}^{\prime}$ and $i_{\mathrm{f}}^{\prime \prime}=c_{\mathrm{f}}^{\prime \prime} t_{\mathrm{f}}^{\prime \prime}$ are, respectively, the enthalpy of the flue gases at the entrance into and exit from the regenerator, $\mathrm{kJ} / \mathrm{m}^{3} ; c_{\mathrm{f}}^{\prime}$ and $c_{\mathrm{f}}^{\prime \prime}$ are, respectively, the specific heats of the flue gases at the temperatures $t_{\mathrm{f}}^{\prime}$ and $t_{\mathrm{f}}^{\prime \prime}, \mathrm{kJ} /\left(\mathrm{m}^{3} \cdot \mathrm{K}\right) ; i_{\mathrm{a}}^{\prime}=c_{\mathrm{a}}^{\prime} t_{\mathrm{a}}^{\prime}$ and $i_{\mathrm{a}}^{\prime \prime}=$ $c_{\mathrm{a}}^{\prime \prime} t_{\mathrm{a}}^{\prime \prime}$ are, respectively, the enthalpy of air at the entrance into and exit from the regenerator, $\mathrm{kJ} / \mathrm{m}^{3} ; c_{\mathrm{a}}^{\prime}$ and $c_{\mathrm{a}}^{\prime \prime}$ are, respec- 

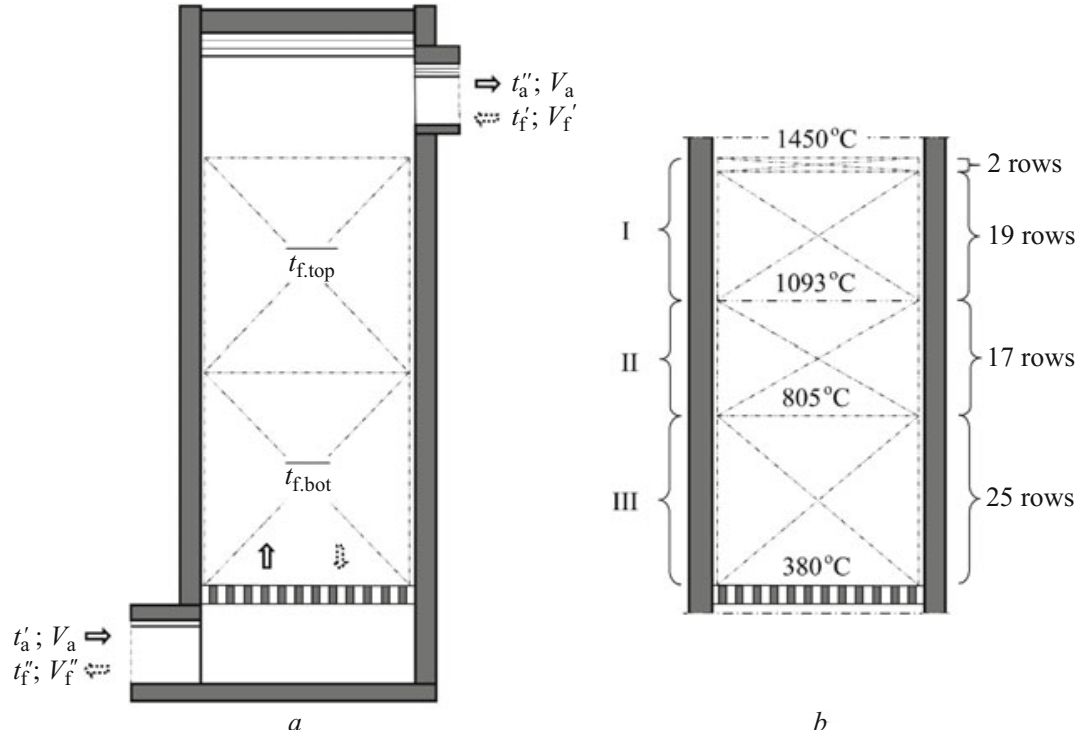

tively, the specific heats of the flue gases at the temperatures $t_{\mathrm{a}}^{\prime}$ and $t_{\mathrm{a}}^{\prime \prime}, \mathrm{kJ} /\left(\mathrm{m}^{3} \cdot \mathrm{K}\right)$; the coefficient $\eta$ takes account of the heat losses through the regenerator brickwork into the ambient environment; $m_{\mathrm{a}}$ is the air intake ratio of the regenerator; $i_{\text {in }}^{\prime}$ and $i_{\text {in }}^{\prime \prime}$ are, respectively, the intake (air) enthalpy at the entrance into and exit from the regenerator, $\mathrm{kJ} / \mathrm{m}^{3}$.

In turn

$$
V_{\mathrm{f}}^{\prime}=V_{\mathrm{p} . \mathrm{c}}+V_{\mathrm{deg}},
$$

where $V_{\text {p.c }}=B V_{\alpha}$ is the flow of the products of combustion of gas, $\mathrm{nm}^{3} / \mathrm{sec} ; V_{\mathrm{deg}}$ is the flow of the products of degassing of the batch, $\mathrm{nm}^{3} / \mathrm{sec}$; and, $V_{\alpha}$ is the amount of products of combustion formed by burning $1 \mathrm{~m}^{3}$ of gas with $\alpha=$ $1.1 \mathrm{~m}^{3} / \mathrm{m}^{3}$.

The flow of flue gases at the exit from the regenerator increases by the air intake amount:

$$
V_{\mathrm{f}}^{\prime \prime}=V_{\mathrm{f}}^{\prime}+m_{\mathrm{a}} V_{\mathrm{f}}^{\prime}
$$

The air intake is distributed approximately uniformly over the height of the regenerator. Therefore it can be assumed that

$$
i_{\text {in }}^{\prime}=i_{\mathrm{a}}^{\prime} \quad \text { and } \quad i_{\text {in }}^{\prime}=0.5\left(i_{\mathrm{f}}^{\prime}+i_{\mathrm{f}}^{\prime \prime}\right) .
$$
$m_{\mathrm{a}}=0.1$.
Fig. 1. Working scheme of the regenerator in a glassmaking furnace (the notation is given in the text): a) for calculating the temperature of the flue gases; $b$ ) for calculating the structure of the checkerwork; I) high-temperature zone; II) condensation zone; III) low-temperature zone.

Taking account of the relations (2) we obtain from Eq. (1) an expression for calculating the enthalpy of flue gases at the exit from the regenerator:

$$
i_{\mathrm{f}}^{\prime \prime}=\frac{V_{\mathrm{f}}^{\prime}\left[i_{\mathrm{f}}^{\prime}\left(1-0.5 m_{\mathrm{a}}\right)+m_{\mathrm{a}} i_{\mathrm{a}}^{\prime}\right]-\frac{1}{\eta} V_{\mathrm{a}}\left(i_{\mathrm{a}}^{\prime \prime}-i_{\mathrm{a}}^{\prime}\right)}{V_{\mathrm{f}}^{\prime}\left(1+0.5 m_{\mathrm{a}}\right)} .
$$

For modern regenerators in glassmaking furnaces with a multilayer energy-efficient brickwork structure $\eta=0.97$ and

The temperatures of the flue gases averaged over one operating cycle of the regenerator for the top and bottom of the checkerwork are

$$
\overline{t_{\text {f. top }}}=0.5\left(t_{\mathrm{f}}^{\prime}+\overline{t_{\mathrm{f}}}\right) ; \quad \overline{t_{\mathrm{f} . \text { bot }}}=0.5\left(t_{\mathrm{f}}^{\prime \prime}+\overline{t_{\mathrm{f}}}\right),
$$

where $\overline{t_{\mathrm{f}}}=0.5\left(t_{\mathrm{f}}^{\prime}+t_{\mathrm{f}}^{\prime \prime}\right)$ is the temperature of the flue gases in the checkerwork averaged over one operating cycle of the regenerator, ${ }^{\circ} \mathrm{C}$.

We shall now determine the parameters $t_{\mathrm{f}}^{\prime \prime}, \overline{t_{\mathrm{f} \text {. top }}}$ and $\overline{t_{\mathrm{f} \text { bot }}}$ of a glassmaking furnace with a horseshoe flame. We use the results of a calculation of fuel combustion and the

TABLE 1. Flow of Flue gases

\begin{tabular}{lcccccc}
\hline \multirow{2}{*}{ Parameter } & \multicolumn{5}{c}{ Components, nm/sec } & Total \\
\cline { 2 - 6 } & $\mathrm{CO}_{2}$ & $\mathrm{SO}_{2}$ & $\mathrm{H}_{2} \mathrm{O}$ & $\mathrm{N}_{2}$ & $\mathrm{O}_{2}$ & 4.726 \\
\hline Products of combustion $V_{\mathrm{p} . \mathrm{c}}$ & 0.424 & - & 0.830 & 3.388 & 0.084 & 0.338 \\
Products of degassing $V_{\text {deg }}$ & 0.203 & 0.004 & 0.131 & - & - & 5.064 \\
$V_{\mathrm{f}}^{\prime}=V_{\mathrm{p} . \mathrm{c}}+V_{\text {deg }}$ & 0.627 & 0.004 & 0.961 & 3.388 & 0.084 & 0.506 \\
Products of intake $\left(m_{\mathrm{a}}=0.1\right)$ & & - & - & 0.400 & 0.106 & 5.570 \\
$\quad V_{\text {in }}=m_{\mathrm{a}} V_{\mathrm{f}}^{\prime}$ & - & - & 0.961 & 3.788 & 0.190 & \\
$V_{\mathrm{f}}^{\prime \prime}=V_{\mathrm{f}}^{\prime}+V_{\text {in }}$ & 0.627 & 0.004 & & & & \\
\hline
\end{tabular}


TABLE 2. Composition of the Flue gases

\begin{tabular}{|c|c|c|c|c|c|c|}
\hline \multirow{2}{*}{ Index } & \multicolumn{5}{|c|}{ Volume composition of flue gases, $\%$} & \multirow{2}{*}{ Total } \\
\hline & $\mathrm{CO}_{2}$ & $\mathrm{SO}_{2}$ & $\mathrm{H}_{2} \mathrm{O}$ & $\mathrm{N}_{2}$ & $\mathrm{O}_{2}$ & \\
\hline $\begin{array}{l}\text { At entrance into } \\
\text { checkerwork }\end{array}$ & 12.38 & 0.08 & 18.98 & 66.90 & 1.66 & 100 \\
\hline $\begin{array}{l}\text { At exit from } \\
\text { checkerwork }\end{array}$ & 11.26 & 0.07 & 17.25 & 68.01 & 3.41 & 100 \\
\hline
\end{tabular}

heat balance of the furnace. The initial data are as follows: $B=0.379 \mathrm{~nm}^{3} / \mathrm{sec}, L_{\alpha}=12.42 \mathrm{~m}^{3} / \mathrm{m}^{3}, \quad V_{\alpha}=12.47 \mathrm{~m}^{3} / \mathrm{m}^{3}$, $t_{\mathrm{f}}^{\prime}=1450^{\circ} \mathrm{C}, t_{\mathrm{a}}^{\prime}=20^{\circ} \mathrm{C}$ and $t_{\mathrm{a}}^{\prime \prime}=1300^{\circ} \mathrm{C}$. The amount and composition of the flue gases at the entrance into and exit from the regenerator are presented in Tables 1 and 2.

The specific heat of the flue gases can be calculated by means of an additive relation using tabulated data on the specific heats of the components. The specific heat of air can be found in handbooks. The results are: $c_{\mathrm{a}}^{\prime}=1.2979, t_{\mathrm{a}}^{\prime \prime}=$ 1.4428 and $c_{\mathrm{f}}=1.6398 \mathrm{~kJ} /\left(\mathrm{m}^{3} \cdot \mathrm{K}\right)$.

The computational results for the enthalpy and temperature of the flue gases are as follows.

\section{Computational Results for the Parameters of the Flue gases}

Enthalpy of the flue gases at the entrance into the regenerator, $\mathrm{kJ} / \mathrm{m}^{3} \ldots \ldots . .2312 .75$

Enthalpy of the flue gases at the exit from the regenerator, $\mathrm{kJ} / \mathrm{m}^{3}$. . . . . . . . . . 542.83

Enthalpy of the air at the entrance into the regenerator, $\mathrm{kJ} / \mathrm{m}^{3} \ldots \ldots . . . . .25 .96$

Enthalpy of the air at the exit from the regenerator, $\mathrm{kJ} / \mathrm{m}^{3}$. . . . . . . . . . 1875.64

Temperature of the flue gases at the entrance into the checkerwork, ${ }^{\circ} \mathrm{C}$. . . . . . . . . . . . 1450

Temperature of the flue gases at the exit from the checkerwork, ${ }^{\circ} \mathrm{C}$. . . . . . . . . . . . 380

Average temperature of the flue gases for the top of the checkerwork, ${ }^{\circ} \mathrm{C}$. . . . . . . 1182.5

Average temperature of the flue gases for the bottom of the checkerwork, ${ }^{\circ} \mathrm{C}$. . . . . . 647.5

For the present example the heated air temperature $1300^{\circ} \mathrm{C}$ is attained with checkerwork surface area $4700 \mathrm{~m}^{3}$. The checkerwork height $11.025 \mathrm{~m}$ is comprised of TL 14/175 pot-like blocks (63 rows). The distribution of the temperature over the height of the checkerwork (Fig. 2) can be fit by the linear function

$$
t=380+97.05 x,
$$

where $x$ is the vertical coordinate of the checkerwork, $\mathrm{m}$.

Thus, on the basis of the assumption made the calculation of the heat transfer through the regenerator brickwork above and beneath the checkerwork must be performed at the temperatures 1450 and $380^{\circ} \mathrm{C}$, respectively. Dividing the brickwork (within the height of the checkerwork) into indi-

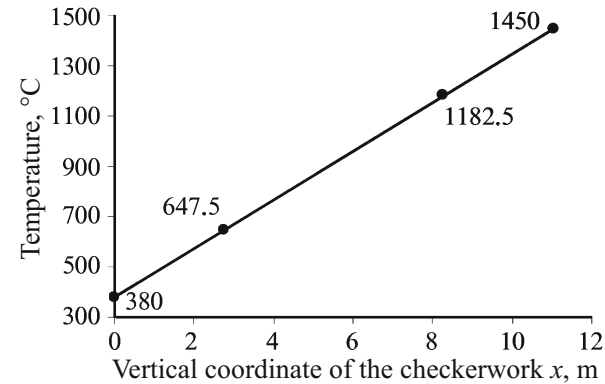

Fig. 2. Distribution of the temperature of the flue gases over the height of the checkerwork of the regenerator.

vidual sections the temperature of the sections is determined using Eq. (2) and the coordinate $x$ of the geometric center of each section.

We shall now examine the application of Eq. (2) for determining the structure of the checkerwork. The requirements for the quality of the materials used for fabricating the checkerwork elements are now understood quite clearly. Their basis is a differential approach to the chemical composition of the refractories, which is based on the characteristics of the transformation of the state of the warming medium and its interaction with the checkerwork material [2].

According to the operating conditions of the refractories the checkerwork can be divided over the height of the regenerator (top - bottom) into three zones (see Fig. 1b). In the present example the checkerwork is assumed to be assembled from TL 14/175 elements (block height $175 \mathrm{~mm}$ ). It includes (top - bottom) 2 rows of RUBINAL VZ (QMZR-12), 19 rows of Anker DG 1 (QMZ-97) and 42 rows of Rubinal EZ (QMZR-12B). The sources of the corrosion on the top rows of the checkerwork in the high-temperature zone $\left(>1100^{\circ} \mathrm{C}\right)$ are mainly dust-like components of the batch. For this reason, the top $2-3$ rows of the checkerwork are fabricated from magnesite-zircon refractory in which the periclase grains are protected by a layer of forsterite and zirconium oxide. An example is RUBINAL VZ and QMZR-12 (Table 3). For all other rows of the checkerwork in this zone the corrosion action of the dust-like components is not criti$\mathrm{cal}$, and the wear of the refractory is determined by its resistance to the high-temperature alkaline gas medium. Periclase articles with high magnesium oxide content $(97 \%)$, for example, Anker DG 1 and QMZ-97 (see Table 3), find applications in this part of the checkerwork.

It should be noted that the operating properties of magnesia refractories are determined not only by the $\mathrm{MgO}$ content but also by the impurity content in the raw material. The mineral impurities containing $\mathrm{CaO}, \mathrm{SiO}_{2}$ and $\mathrm{Fe}_{2} \mathrm{O}_{3}$ are especially dangerous. A small quantity of silica forms in articles a forsterite binder, which increases the temperature of deformation under load. For a high content of $\mathrm{SiO}_{2}$ and $\mathrm{CaO} / \mathrm{SiO}_{2}<1$ low-melting compounds - monticellite $\mathrm{CaMgSiO}_{4}$ or merwinite $\mathrm{Ca}_{3} \mathrm{Mg}\left(\mathrm{SiO}_{4}\right)_{2}$ - are formed. The reactions with low-melting compounds result in the forma- 
TABLE 3. Characteristics of the Magnesia Articles for the Checkerwork of the Regenerator

\begin{tabular}{|c|c|c|c|c|c|c|}
\hline \multirow{3}{*}{ Index } & \multicolumn{6}{|c|}{ Refractory brand } \\
\hline & \multicolumn{3}{|c|}{ RHI Refractories (Austria) } & \multicolumn{3}{|c|}{ Qinghua Refractories (China) } \\
\hline & Rubinal VZ & Anker DG 1 & Rubinal EZ & QMZR-12 & QMZ-97 & QMZR-12B \\
\hline \multicolumn{7}{|l|}{ Mass fraction, $\%$} \\
\hline $\mathrm{MgO}$ & 78.00 & 97.00 & 75.10 & 78.38 & 96.60 & 78.17 \\
\hline $\mathrm{SiO}_{2}$ & 8.00 & 0.60 & 10.00 & 6.85 & 0.90 & 7.00 \\
\hline $\mathrm{CaO}$ & 0.60 & 1.60 & 1.20 & - & 1.30 & - \\
\hline $\mathrm{Fe}_{2} \mathrm{O}_{3}$ & 0.40 & 0.50 & 0.50 & - & - & - \\
\hline $\mathrm{Al}_{2} \mathrm{O}_{3}$ & - & - & - & - & - & - \\
\hline $\mathrm{ZrO}_{2}$ & 13.50 & - & 13.00 & 12.38 & 12.38 & 12.76 \\
\hline Apparent density, $\mathrm{g} / \mathrm{cm}^{3}$ & 3.19 & 2.96 & 3.10 & 3.18 & 2.96 & 3.16 \\
\hline Porosity, \% & 11.0 & 15.9 & 14.5 & 13.1 & 15.2 & 13.6 \\
\hline $\begin{array}{l}\text { Temperature of deformation } \\
\text { under a load, }{ }^{\circ} \mathrm{C}\end{array}$ & 1670 & $>1700$ & 1570 & 1680 & 1700 & 1650 \\
\hline Ultimate strength in compression, $\mathrm{MPa}$ & 90 & 70 & 90 & 75 & 88 & 70 \\
\hline
\end{tabular}

tion of calcium orthosilicate $\mathrm{Ca}_{2} \mathrm{SiO}_{4}$. In the presence of $2-5 \% \mathrm{CaSiO}_{4}$ the periclase refractories crumble. This is related with the stresses due to the increase in the volume of the articles by $10-12 \%$ as a result of the modification transition of $\beta-\mathrm{Ca}_{2} \mathrm{SiO}_{4}$ into the $\gamma$ form. In magnesia refractories, as the ratio $\mathrm{CaO} / \mathrm{SiO}_{2}>1$ increases the high-temperature strength of the articles increases and reaches a maximum at $\mathrm{CaO} / \mathrm{SiO}_{2} \approx 2$.

In the temperature interval $1100-800^{\circ} \mathrm{C}$ alkali and alkaline-earth metal sulfates condense in the flue gases. They infiltrate the structure of the refractory blocks. In the process the blocks become denser, while the elasticity of the structure and the resistance of the blocks to temperature differentials decrease. As a result refractory articles crumble because of so-called sulfate swelling. The lowest rows of the zone are subjected to intense slagging by the products of condensation.

Checkerwork made from magnesia-zircon refractories of the type Rubinal EX and QMZR-12B (see Table 3) are effective in the condensation zone. The binding matrix of these refractories consists of forsterite and zirconium oxide. Here periclase crystals are also protected by a layer of forsterite and zirconium oxide. Neither component is subjected to attack by sodium sulfate.

During the venting period, at flue-gas temperatures below $800^{\circ} \mathrm{C}$ the checkerwork is subjected mainly to thermal cycling and less to aggressive condensing sulfate compounds. During thermal cleaning of the checkerwork in the condensation zone the products of fusion come into contact with the checkerwork in the low-temperature zone. For this reason the Rubinal EZ and QMZR-12B magnesia-zircon refractories are used in this zone also.

In summary, in designing the structure of the checkerwork of the regenerator the critical parameter is the position of the bottom boundary of the high-temperature zone, whose coordinate is determined from Eq. (2).

\section{REFERENCES}

1. M. D. Kazyaev, S. N. Gushchin, V. I. Lobanov, et al., Fundamentals of the Theory of Heat Generation [in Russian], UGTU, Ekaterinburg (1999).

2. V. Ya. Dzyuzer, "Refractories for regenerators of glassmaking furnaces," Ogneup. Tekh. Keram., No. 6, 22 - 26 (2008). 